\title{
Performance of Reactive Powder Concrete Containing Arsenic
}

\author{
Sreedevi Ande ${ }^{1}$, Bruce Berdanier ${ }^{2}$, Venkataswamy Ramakrishnan ${ }^{3}$ \\ ${ }^{1}$ Department of Mathematics, Engineering \& Computer Science, LaGuardia Community College, New York, USA \\ ${ }^{2}$ Department of Civil and Environmental Engineering, South Dakota State University, Brookings, USA \\ ${ }^{3}$ Civil and Environmental Engineering Department, South Dakota School of Mines \& Technology, Rapid City, USA \\ E-mail:sande@lagcc.cuny.edu, Bruce.Berdanier@sdstate.edu, Venkataswamy.Ramakrishnan@sdsmt.edu \\ Received January 31, 2011; revised March 5, 2011; accepted April 9, 2011
}

\begin{abstract}
A mixture of arsenic contaminated soil and reactive powder concrete (RPC) was developed to study the effect of arsenic contaminated soil on RPC mortar and the effectiveness of the mortar in containing the contaminant. The sufficient containment of arsenic contaminated waste products is important to protection of ground and surface water sources. A three phase experiment was designed to study the permeability, absorption coefficients, and Toxicity Characteristic Leaching Procedure (TCLP) leachate concentrations resulting from the application of a range of arsenic concentrations. The results showed that the permeability values for mixes containing different arsenic concentrations did not increase noticeably with adequate curing time. The percentage of absorption slightly increased with increasing arsenic content as did the TCLP leachate concentrations. Statistical analyses, Analysis of Variance (ANOVA) and Paired T-test, were performed to analyze percent absorption, and TCLP results. Based on the results it was concluded that percent absorption decreased significantly with increase in curing time. Although, the TCLP concentrations increased with increased curing time, the increase was not statistically significant.
\end{abstract}

Keywords: Arsenic, Concrete, Curing, Leaching, Tests

\section{Introduction}

Studies have shown that stabilization/solidification technology processes for treatment of contaminated soils/ residues has been successful in stabilizing a wide variety of materials including metals, volatiles, waste oils and solvents creating a hard, soil-like material binding free liquids and chemicals [1-3]. Stabilization/solidification technologies are economical and can include in-situ and ex-situ treatment methods $[4,5]$.

According to Silveira et al., "Cement-based solidification/stabilization is a process in which inorganic reagents react with waste components and/or themselves to form chemically stable solids which are capable of developing mechanical resistance" [6]. Treatment processes using Portland cement, a major inorganic reagent, have been successful in immobilizing constituents of environmental concern [7,8]. Portland cement produces a hardened paste upon addition of water. This paste binds together aggregates and other substances to form concrete and stabilize wastes $[9,10]$ This technology is currently being used to treat a wide variety of wastes and showed to be effective in reducing the mobility of arsenic wastes [11,12].

This research project tested the use of Reactive Powder Concrete (RPC), an ultra high-strength and low porosity composite material with advanced mechanical and superior physical properties [13,14] for encapsulating arsenic contaminated soil.

The main objective was to study water permeability and absorption of RPC during the storage of inorganic material, arsenic, by application of a solidification/stabilization technique. Arsenic contaminated soil was encapsulated in RPC to determine the maximum concentration of arsenic in soil, which allowed formation of acceptable permeability, and leachate concentration less than 10 parts per billion (ppb) when encapsulated in RPC mortar.

This study tested the hypothesis that RPC would provide a better performing containment and disposal solution for solidifying arsenic contaminated soils as compared to solidification with cement mortar. 


\section{Study of Arsenic-Contaminated Soils}

Arsenic is a naturally occurring toxic element in the earth's crust, which forms inorganic arsenic when combined with oxygen, chlorine and sulfur. Additionally, arsenic combined with carbon and hydrogen forms organic arsenic. The inorganic forms of arsenic are much more toxic than organic forms. The principal valence states of arsenic are $+3,+5$, and -3 . [15] Arsenical pesticides, natural geothermal sources and mine tailings increase arsenic concentrations in soils. The adsorption of arsenicals in soil depends on soil $\mathrm{pH}$, texture, $\mathrm{Fe}, \mathrm{Al}$, and organic matter. The amount of arsenic adsorbed on soil increases as clay, $\mathrm{Fe}$, and $\mathrm{Al}$ content increases. Toxic amounts of arsenic, greater than 10 parts per million (ppm) in soils will limit the germination of seeds and reduce the viability of seedlings. Organic arsenic is used in catalysts, glass manufacturing, alloys, electronics and weed killer. Inorganic forms of arsenic are also used in pesticides to kill insects or rodents, to preserve wood, and as a component of medicines for asthma and psoriasis. Arsenic levels in municipal sewage are variable from 1 - 18 ppm [16]. An upper limit of 0.2 ppm is recommended for as in livestock drinking water and an upper limit of $0.01 \mathrm{ppm}$ for water intended for human consumption. In soils, the total as concentration normally ranges from 1 - $40 \mathrm{ppm}$. [17]

Arsenic contamination resulting from natural or xenobiotic sources in ground and surface waters is a major health concern for water designated for agricultural or human consumption uses. A great deal of time and money is being expended to conduct research and development of processes for removal of arsenic from such waters to concentrations as low as $5 \mathrm{ppb}$.

This study represents the first evaluation of the solidification/stabilization technique using RPC and its capability in containing arsenic. This research determined the maximum concentration of arsenic in soil that resulted in the lowest water permeability, and a leachate concentration less than the current drinking water standard. This study provides operational boundaries for the initiation of a more detailed study of arsenic encapsulation in structural concrete.

A sludge having arsenic concentration of 2000 ppm when treated by incineration or landfill process was reported to lead to volatilization, ecosystem cycling, ground water and air contamination [18,19]. Therefore, application of a solidification/stabilization process using RPC as an additive to effectively encapsulate contaminated material and to produce a stabilized engineered product, which contains toxic products in a less soluble state, would be an important advancement.

\section{Materials}

The cement used was Type I/II supplied by Dacotah Cement, South Dakota. The fine aggregate used for all the mixes (limestone dust and natural sand) were obtained form Hill City Materials, Rapid City, South Dakota. Commercially prepared topsoil was purchased for this study. Tap water from the Rapid City Municipal water supply system was used for the mixing. The admixtures such as Rheomac SF 100 dry, a densified silica fume, and Glenium 3000 NS, a high range water reducer (HRWR), were both supplied by Master Builders Inc, Cleveland Ohio. The contaminant encapsulated in topsoil was sodium arsenate $\left(\mathrm{Na}_{2} \mathrm{HAsO}_{4} \cdot 7 \mathrm{H}_{2} \mathrm{O}\right)$.

\subsection{Tests on Topsoil Absorption Coefficient}

Before using the topsoil for mixing, the adsorption coefficient of the topsoil was determined using the standard procedures given by ASTM C128 [20]. The absorption of topsoil was $58.43 \%$. The absorption \% of soil was subtracted from the moisture content to calculate the actual proportion of soil to be used for mixing mortar on wet basis.

\subsection{Organic Matter and Carbon Content}

The soil samples were sent to Soil Testing Laboratory, South Dakota State University for determination of organic matter and carbon content. The results are shown in Table 1.

\subsection{Experimental Design}

The statistical software package, Minitab, was used to determine a hierarchical design resulting in a series of nine RPC mortar mixes which were tested and the mix having Water-Cement ratio (W/C) of 0.275 , limestone/cement of 0.3 , silica fume/cement of 0.39 was chosen due to its lowest permeability and highest strength. This mix was then evaluated by holding the amount of cement, limestone, silica fume and W/C constant while soil was substituted at $10,15,20,30,40,50$ and $100 \%$ of

Table 1. Organic matter and organic carbon content for soil samples.

\begin{tabular}{ccc}
\hline Sample ID & Organic matter (\%) & Organic carbon (\%) \\
\hline Sample 1 & 14.1 & 8.18 \\
Sample 2 & 22.1 & 12.82 \\
Sample 3 & 23.4 & 13.57 \\
Average & 19.9 & 11.52 \\
\hline
\end{tabular}


sand and again evaluated for permeability and strength resulting in the choice of $20 \%$ soil. Finally, the chosen RPC mortar mix was evaluated with the $20 \%$ soil component dosed with arsenic concentrations of 100, 1000, 2000, and $3000 \mathbf{~ m g / k g}$.

\subsection{Specimens}

Specimens of $50.8 \mathrm{~mm} \times 50.8 \mathrm{~mm} \times 50.8 \mathrm{~mm}$ were made following the ASTM C 305-94 standard [21]. The cubes were tested for compressive strength in accordance with the Standard test method for compressive strength of mortars given by ASTM C 109-93 [22]. Additionally, cylinders with a diameter of $101.6 \mathrm{~mm}$ and length $203.2 \mathrm{~mm}$ were cast. The cylinders were cut in $50.8 \mathrm{~mm}$ slices and a Rapid Chloride Permeability Test (RCPT) was completed in accordance with ASTM C 1202 along with an absorption test in accordance with ASTM C 497. The Toxicity Characteristic Leaching Procedure (TCLP) test samples were prepared following the EPA Method 1311 [23].

\section{Results and Discussion}

\subsection{TCLP Results on the Raw Materials}

The TCLP test results performed on cement, limestone dust, fine sand, uncontaminated soil and silica fume indicated that no arsenic was present in these materials. Therefore, the results of the TCLP test performed for the last phase are representative of the arsenic which leached from the contaminated soil used in the mix preparation.

\subsection{Permeability and Absorption Results for Varying Soil Mixes}

The 56 and 90 day permeability for varying soil mixes are shown in the Table 2. It was observed that the permeability increased with the increase in the soil content.
Figure 1 shows that the percent absorption increased with the increase in soil content in the mixes and remained approximately constant at 7, 28 and 45 day curing.

\subsection{Permeability, Absorption, and TCLP Results for Arsenic Contaminated Mixes}

RPC mixtures were made containing $20 \%$ soil dosed with arsenic of 100,1000, 2000, and $3000 \mathrm{mg} / \mathrm{kg}$ of soil, respectively.

The permeability test results conducted on the arsenic contaminated samples at 56 and 90 days are shown in Table 3. The results showed that the permeability values for mixes containing different concentrations of arsenic did not show considerable increase after 56 and 90 day curing.

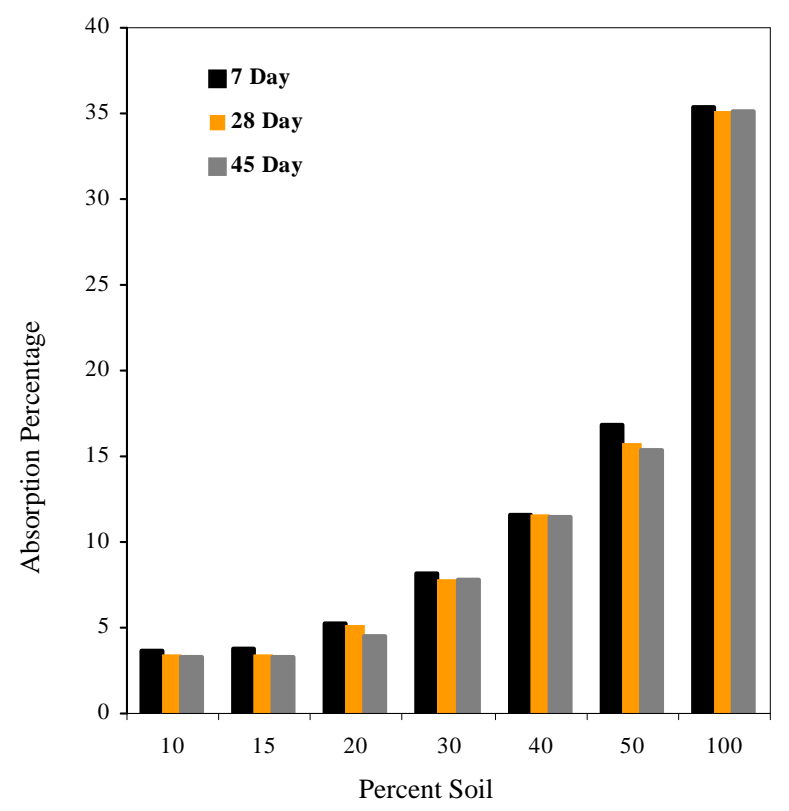

Figure 1. Absorption percentage as affected by soil content.

Table 2. Permeability of mixes with varying soil proportions.

\begin{tabular}{|c|c|c|c|c|c|c|c|}
\hline $\begin{array}{l}\text { Mix } \\
\text { ID }\end{array}$ & $\begin{array}{c}\text { Soil Content } \\
\text { \% } \\
\end{array}$ & $\begin{array}{l}\text { Age } \\
\text { (Days) }\end{array}$ & $\begin{array}{l}\text { Permeability } \\
\text { (Coulombs) }\end{array}$ & $\begin{array}{c}\text { Remarks } \\
\text { ASTM C } 1202 \text { Classified }\end{array}$ & $\begin{array}{l}\text { Age } \\
\text { (Days) }\end{array}$ & $\begin{array}{l}\text { Permeability } \\
\text { (Coulombs) }\end{array}$ & $\begin{array}{c}\text { Remarks } \\
\text { ASTM C } 1202 \text { Classified }\end{array}$ \\
\hline M1S1 & 10 & 56 & 122 & Very Low & 90 & 52 & Negligible \\
\hline M1S2 & 15 & 56 & 138 & Very Low & 90 & 77 & Negligible \\
\hline M1S3 & 20 & 56 & 175 & Very Low & 90 & 90 & Negligible \\
\hline M1S4 & 30 & 56 & 199 & Very Low & 90 & 100 & Negligible \\
\hline M1S5 & 40 & 56 & 251 & Very Low & 90 & 110 & Very Low \\
\hline M1S6 & 50 & 56 & 358 & Very Low & 90 & 173 & Very Low \\
\hline M1S7 & 100 & 56 & 946 & Very Low & 90 & 401 & Very Low \\
\hline
\end{tabular}


The percent absorption is shown in Figure 2. It was observed that the percent absorption for mixes containing arsenic was high compared to the percent absorption of M1S3 mix, which contained uncontaminated organic soil. The increase could be due to inadequate hydration of cement at early stages due to the water added during mixing being absorbed by arsenic, which was encapsulated in the mortar. It was also observed that the percent absorption appeared to decrease with curing time, which shows that the pores are filled in the due course of time.

The 7, 28 and 56 day TCLP results in Figure 3 showed that the arsenic concentrations leaching out from mortar specimens increased with the increase in the initial concentrations.

The leachate concentration for the mix M1S3.A4 was very high at 7 day curing, which could be due to an experimental error. From the results, it can be observed that with increased curing time the TCLP concentrations ap- peared to increase slightly. The increase in leachate concentrations decreased with an increase in curing time i.e., the percent increase for the 100 and 1000 mixes from 7 to 28 and 28 and 56 curing days decreased from $128 \%$ to $23 \%$ and from $69 \%$ to $23 \%$ respectively. There was an insignificant increase in TCLP concentration for the 2000 mix from 7 to 28 days curing but appeared to increase by $28 \%$ after 56 days curing.

The TCLP leaching concentrations for all the mixes were below the EPA drinking water limit of $10 \mathrm{ppb}$, which showed that the arsenic concentrations of 100 , 1000,2000 , and $3000 \mathrm{mg} / \mathrm{kg}$ of soil may be permissible concentrations for encapsulating in concrete.

\section{Statistical Analysis}

Linear regression analysis was performed on all of the data in order to determine the statistical significance of

Table 3. Permeability results for the mixes M1S3.A1-M1S3.A4 containing arsenic.

\begin{tabular}{ccccccc}
\hline $\begin{array}{c}\text { Mix } \\
\text { ID }\end{array}$ & $\begin{array}{c}\text { Age } \\
\text { (Days) }\end{array}$ & $\begin{array}{c}\text { Permeability } \\
\text { (Coulombs) }\end{array}$ & $\begin{array}{c}\text { Remarks } \\
\text { ASTM C 1202 Classified }\end{array}$ & $\begin{array}{c}\text { Age } \\
\text { (Days) }\end{array}$ & $\begin{array}{c}\text { Permeability } \\
\text { (Coulombs) }\end{array}$ & $\begin{array}{c}\text { Remarks } \\
\text { ASTM C 1202 Classified }\end{array}$ \\
\hline 100 & 56 & 168 & Very Low & 90 & 83 & Negligible \\
1000 & 56 & 180 & Very Low & 90 & 94 & Negligible \\
2000 & 56 & 186 & Very Low & 90 & 99 & Negligible \\
3000 & 56 & 196 & Very Low & 90 & 102 & Very Low \\
\hline
\end{tabular}

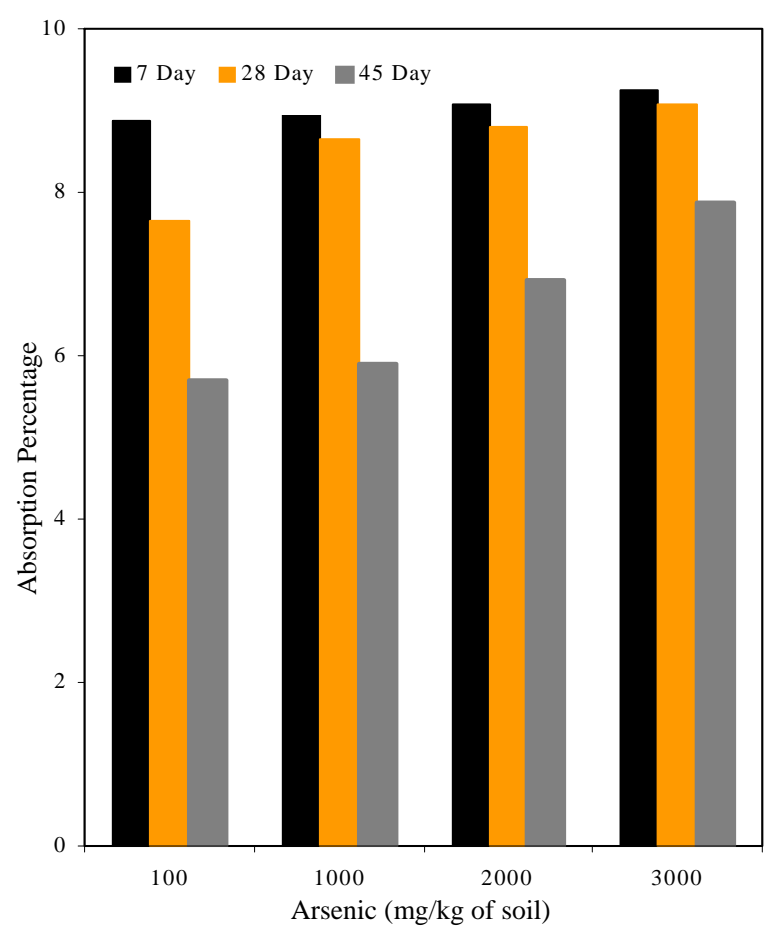

Figure 2. Absorption percentage as affected by arsenic content.

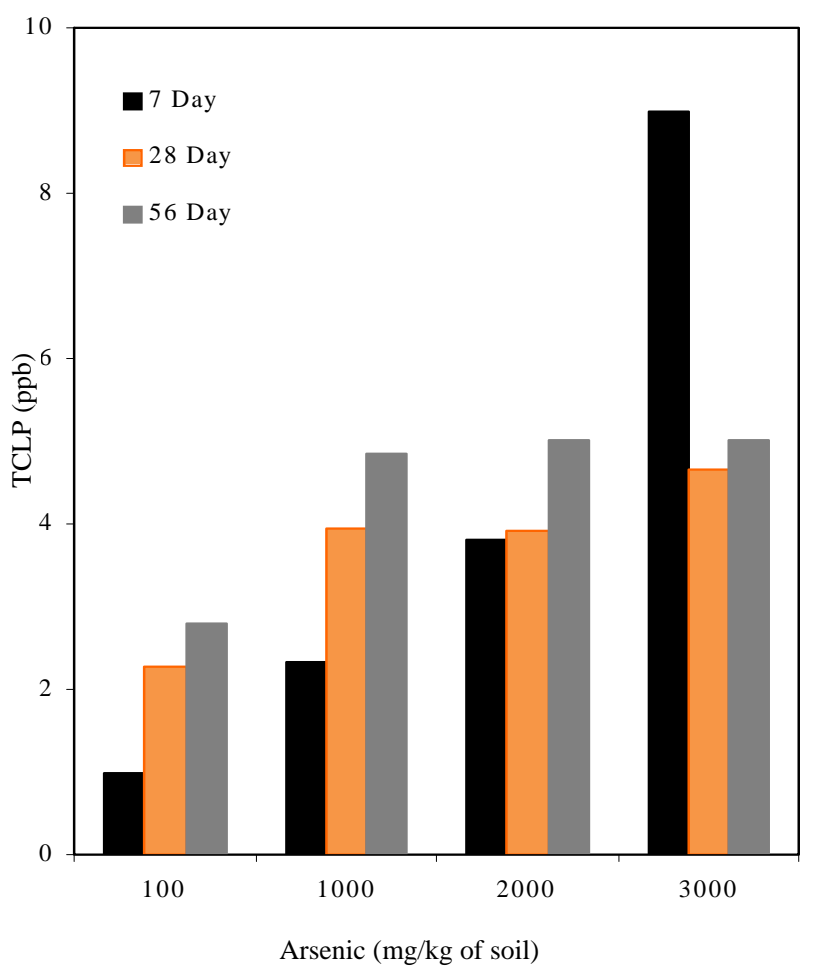

Figure 3. TCLP as affected by arsenic content. 
experimental results that were obtained for each mix with respect to curing period. One-way analysis of variance (ANOVA) using statistical software was performed for each mixture. Resultant $\mathbf{p}$ values were considered significant if they indicated that the hypothesis-that the means were equivalent-could be rejected at a level lower than 0.05 .

The experimental percent absorption values for all of the mixes obtained at 7, 28 and 45 days appeared to decrease with increased curing time. From the $\mathrm{p}$ values obtained from ANOVA, it was concluded there was statistical evidence to support the conclusion that percent absorption for all of the mixes decreased from 7 days to 45 days.

The experiments showed that the TCLP leachate concentrations for all four of the mixes appeared to increase from 7 to 56 day curing. The experimental results showed that the TCLP leachate concentrations of the 3000 mix were high at 7 days curing, which could be due to an experimental error. Therefore, the statistical analyses were performed on TCLP concentrations between 28 and 56 days. The $\mathrm{p}$ values from one-way ANOVA for the all the mixes were greater than 0.05 at the $95 \%$ confidence level, which indicated that the increase in TCLP concentrations was statistically insignificant with curing time.

\section{Conclusions}

Based on the results of this study, the following conclusions can be made:

The permeability test for third phase mixes with $20 \%$ soil and varying arsenic concentrations, 100, 1000, 2000 and $3000 \mathbf{~ m g} / \mathbf{k g}$ of soil, conducted at the ages of 56 and 90 days showed that there was a slight increase in the permeability with the increase in the arsenic concentration. At 56 day age the permeability was "Very Low" and was "Negligible" at the age of 90 days.

The absorption slightly increased for the mixes containing arsenic, which could be due to the arsenic absorbing the water. No significant changes were observed in the permeability of the arsenic contaminated mixes. All the mixes were considered to have "Very Low" permeability at 56 days and "Negligible" at 90 days except for the mix containing $3000 \mathbf{~ m g / k g}$ of arsenic concentration, which had "Very Low" permeability even at 90 days.

The TCLP results indicated that the leaching concentrations increased for all the mixes with increased curing time but were below the proposed EPA drinking water limit of $10 \mathrm{ppb}$, which showed that arsenic encapsulated concrete can be a disposal solution.

\section{References}

[1] B. D. Bone, et al., "Guidance on the Use of Stabilization/Solidification for the Treatment of Contaminated Soil,” Science Report: SC980003/SR1, Environmental Agency, Bristol, 2004.

[2] A. Al-Tabbaa and A. S. R. Perera, "Stabilization/Solidification Treatment and Remediation," Taylor and Francis Group, London, 2005. doi:10.1201/9781439833933

[3] G. R. Qian, J. Shi, Y. L. Cao, Y. F. Xu and P. C. Chui, "Properties of MSW Fly Ash-Calcium Sulfoaluminate Cement Matrix and Stabilization/Solidification on Heavy Metals,” Journal of Hazardous Materials, Vol. 152, No. 1, 2008, pp. 196-203. doi:10.1016/j.jhazmat.2007.06.118

[4] US Environmental Protection Agency, "Solidification/ Stabilization Resource Guide,” EPA Contract Number: 542-B-99-002, 1999.

[5] US Environmental Protection Agency, "Solidification/ Stabilization and Its Application to Waste Materials,” EPA Contract Number: 530/R-93/012, 1993.

[6] B. I. Silveira, A. E. M. Dantas, J. E. M. Blasques and R. K. P. Santos, "Effectiveness of Cement-Based Systems for Stabilization and Solidification of Spent Pot Liner Inorganic Fraction,” Journal of Hazardous Materials, Vol. 98, No. 1-3, 2003, pp. 183-190. doi:10.1016/S0304-3894(02)00317-5

[7] B. C. Willis, M. M. Howie and R. C. Williams, "Public Health Reviews of Hazardous Waste Thermal Treatment Technologies-A Guidance Manual for Public Health Assessors,” Agency for Toxic Substances and Disease Registry, Division of Health Assessment and Consultation, Atlanta, 2002.

[8] M. D. Lagrega, P. L. Buckingham and J. C. Evens, "Hazardous Waste Management,” McGraw-Hill, Boston, 1994.

[9] J. R. Conner, "Guide to Improving the Effectiveness of Cement-Based Solidification/Stabilization,” Portland Cement Association, Skokie, 1997.

[10] A. Adaska, S. W. Tresouthick and P. B. West, "Solidification/Stabilization of Wastes Using Portland Cement," Portland Cement Association, Skokie, 1998.

[11] S. Dawadi, M. R. Hansen and B. W. Berdanier, "Encapsulation of Contaminated Soil in Concrete Mortar,” American Concrete Institute Materials Journal, Vol. 101, No. 5, 2004, pp. 347-352.

[12] M. Leist, R. J. Casey and D. Caridi, "The Fixation and Leaching of Cement Stabilized Arsenic," Waste Management, Vol. 23, No. 4, 2003, pp. 353-359.

[13] E. F. O'Neil, C. E. Dauriac, J. A. Bickley and S. K. Gilliland, "Development of Reactive Powder Concrete Products in the United States Construction Market, an International Perspective,” American Concrete Institute, Farmington Hills, 1995.

[14] F. K. J. Miller, H. Akhter, F. K. Cartledge and M. McLearn, "Treatment of Arsenic-Contaminated Soil. II: Treatablity Study and Remediation,” Journal of Environmental Engineering, Vol. 126, No. 11, 2000, pp. 1004-1012. 
doi:10.1061/(ASCE)0733-9372(2000)126:11(1004)

[15] US Environmental Protection Agency, "Handbook of Ground Water, Volume I: Ground Water and Contamination,” EPA Contract Number: 625/6-90/016a, Washington, 1990.

[16] M. Leist, R. J. Casey and D. Caridi, "The Management of Arsenic Wastes: Problems and Prospects," Journal of Hazardous Materials, Vol. 76, No. 1, 2000, pp. 125-138. doi:10.1016/S0304-3894(00)00188-6

[17] US Environmental Protection Agency, "EPA to Implement $10 \mathrm{ppb}$ Standard for Arsenic in Drinking Water," Ground Water and Drinking Water, EPA Contract Number: 815-F-01-010, 2001.

[18] D. K. Bhumbla and R. F. Keefer, "Arsenic Mobilization and Bioavailability in Soils,” In: J. O. Nriagu, Ed., Arsenic in the Environment, Part I: Cycling and Characterization, John Wiley \& Sons, Inc., Hoboken, 1994, pp. 51-82.

[19] US Environmental Protection Agency, "Locating and Estimating Air Emissions from Sources of Arsenic and
Arsenic Compounds,” Office of Air Quality, EPA Contract Number: EPA-454/R-98-013, 1998.

[20] American Society for Testing and Materials (ASTM), "ASTM C 128-97 - Standard Test Methods for Specific Gravity and Absorption of Fine Aggregate,” Annual Book of ASTM Standards, ASTM International, West Conshohocken, 1997.

[21] American Society for Testing and Materials (ASTM), "ASTM C 305-94 - Standard Practice for Mechanical Mixing of Hydraulic Cement Pastes and Mortars of Plastic Consistency," Annual Book of ASTM Standards, ASTM International, West Conshohocken, 1994.

[22] American Society for Testing and Materials (ASTM), "ASTM C 109-93 - Standard Test Method for Compressive Strength of Hydraulic Cement Mortars,” Annual Book of ASTM Standards, ASTM International, West Conshohocken, 1993.

[23] US Environmental Protection Agency, "SW-846 - Test Methods for Evaluating Solid Waste, Physical/Chemical Methods,” Office of Solid Waste, Washington, 1990. 